\title{
¿Qué pueden hacer las AFPs para contribuir a mitigar la crisis económica que está
}

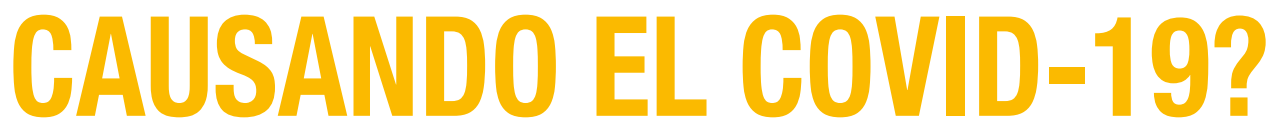

\section{Prácticamente todos los días surgen noticias relacionadas con las Administradoras de Fondos Previsionales (AFPS). ¿Qué hace que la institución de la administración de fondos para la jubilación genere tanto interés público? ¿Cuál es el tamaño agregado de los fondos administrados? ¿En qué invierten las AFPs? ¿Cómo podrían contribuir las AFPs a las empresas nacionales ante la crisis económica causada por el Covid-19?}

Rafael Romero M., Doctor of Business Administration, Questrom School of Business, Boston University, EE.UU. Académico FEN-UAH

LA INSTITUCIÓN DE LA ADMINISTRACIÓN DE FONDOS PARA LA JUBILACIÓN

Las AFPs nacen el año 1980 en Chile, año de la reforma previsional, cuando se diseña el nuevo sistema de fondo de pensiones (dictado por el Decreto Ley $\mathrm{N}^{0}$ 3.500), que actualmente es administrado por siete entidades privadas de capitalización individual. En el año 2002 la Ley № 19.795 modificó el DL 3.500 para introducir el sistema de multifondos.

De esta manera, el espectro de posibilidades de inversión de las AFPs, está dado por: el DL 3.500, el Régimen de Inversión de los Fondos de Pensiones y por la normativa complementaria dictada por la Superintendencia de Pensiones.

Hay diversos actores involucrados en la supervisión de las AFPs, entre ellos están: - Comisión para el Mercado Financiero (CMF), institución encargada de fiscalizar todas las actividades y entidades que participan en los mercados de valores y seguros de Chile.

- Banco Central (BC), que regula y determina parte de los límites estructurales del Sistema de Pensiones, referidos al porcentaje máximo de inversión.

- Superintendencia de Pensiones (SP), organismo del Estado, contralor, regulador fiscalizador y técnico, cuyo objetivo es supervigilar y controlar el Sistema de Pensiones.
- Consejo Técnico de Inversiones (CTI), que fue creado por la reforma previsional de 2008, bajo el 1er Gobierno de Michelle Bachelet. Su objetivo principal es realizar informes, propuestas y pronunciamientos respecto de las inversiones de los fondos de pensiones, procurando el logro de una adecuada rentabilidad y seguridad para éstos.

- Comisión Clasificadora de Riesgo (CCR), organismo al que le corresponde aprobar un conjunto de instrumentos para la inversión de los Fondos de Pensiones. Particularmente, debe aprobar las cuotas de fondos mutuos y fondos de inversión nacionales y los instrumentos representativos de capital extranjeros.

El desempeño promedio entre 2010 y 2019, de los cinco Fondos en términos reales ha sido positivo. Es decir, luego de descontada la variación porcentual de la UF, que sigue a la variación del Índice General de Precios de la economía, la rentabilidad del promedio de los cinco fondos es mayor que cero.

La Tabla 1 presenta las tasas reales de retornos anuales de los últimos 10 años. Con esta información es posible calcular la cantidad que se podría haber acumulado en una cuenta de ahorro individual durante este período de tiempo. Supongamos que el 1 de enero de 2010 se deposita, en alguno de los Fondos, $\$ 1.000 .000$, equivalente a UF 47,7567. ¿Cuántas UFs y Pesos se podrían haber acumulado en el lapso de 10 años?

Una forma de calcular el valor final después de 10 años, es multiplicar la inversión inicial por 1 más la rentabilidad anual de cada año, o multiplicando este valor $10 \mathrm{ve-}$ ces por 1 más la tasa promedio geométrica que se presenta en la Tabla 2.

Por ejemplo, para el Fondo $A$, UF 47,7567 invertidos el 1 de enero de 2010, se convertirían en UF 76,8147 al 31 de diciembre de 2019, equivalente a $\$ 2.174 .619$; es decir, que la rentabilidad nominal acumulada fue de $117,46 \%$. Pero, si los UF 47,7567 son invertidos el 1 de enero de 2010 en el Fondo $E_{\text {, al }} 31$ de diciembre de 2019 se obtendrían UF 73,076, 0 equivalente a $\$ 2.068 .776$, lo que significa una rentabilidad nominal acumulada de $106,88 \%$. Si repitiéramos el ejercicio para los otros tres fondos, el resultado se mantendría. Es decir, la inversión inicial en términos nominales se habría más que duplicado.

A pesar de estos importantes desempeños financieros, las AFPs reciben múltiples críticas, tales como:

- Las pensiones que proveen son muy bajas.

- Las rentabilidades sobre el patrimonio de las empresas que administran los fondos son muy elevadas $y$, además, no están correlacionadas con el desempeño de la rentabilidad de los fondos que administran.

- Los fondos han ayudado a financiar principalmente a los grandes grupos económicos.

- Dada la caída de las bolsas a nivel mundial de marzo de 2020, con la consecuente pérdida financiera para los fondos administrados, se cuestiona la gestión de las AFPs.

Si bien el foco de este artículo no es discutir la veracidad de estas críticas, es importante tomarlas en cuenta debido a que reflejan la percepción de la población en cuanto al desempeño de las AFPs, lo cual permite tener un parámetro a considerar toda vez que se pretende analizar el aporte de las AFPs en inversiones en empresas chilenas en una situación de crisis económica.

\section{MONTOS ADMINISTRADOS POR LOS FONDOS DE PENSIONES}

Durante el primer semestre del año 2019, los ahorros previsionales llegaron a un valor histórico de US\$218.706 millones, debido a la mayor rentabilidad acumulada durante la última década, llegando a representar un 77\% del PIB nacional. Lo anterior se debe a los altos rendimientos obtenidos por una cartera de inversiones diversifica$\mathrm{da}$, centrada en una mayor proporción en el mercado de renta variable internacional y en menor medida en el mercado local complementada con instrumentos de renta fija local e internacional.

\section{EN QUE INVIERTEN LAS AFPS}

El sistema de multifondos consiste en que cada administradora crea cinco Fon$\operatorname{dos}(A, B, C, D$ y E). Las principales clases genéricas de activos son: Renta Fija (bonos estatales, de empresas y bancarios, letras hipotecarias) y Renta Variable (acciones, activos alternativos, fondos de inversión). La desagregación de las categorías de Renta Fija y Renta Variable, nacional e Internacional, se presenta en la Tabla 3

Cada fondo tiene una cartera representativa, la cual está establecida en el D.L. 3.500 y en el Régimen de Inversión de los Fondos de Pensiones. Por lo tanto, existe una diferenciación entre los distintos tipos de fondos, cuya característica se basa en la

Tabla 1: Rentabilidad real de los fondos de pensiones deflactada por la UF

\begin{tabular}{|c|c|c|c|c|c|c|c|c|c|c|}
\hline Tipo de fondo & 2019 & 2018 & 2017 & 2016 & 2015 & 2014 & 2013 & 2012 & 2011 & 2010 \\
\hline Fondo $\mathrm{A}$ & $17,26 \%$ & $-5,59 \%$ & $15,44 \%$ & $-0,87 \%$ & $3,79 \%$ & $8,86 \%$ & $6,79 \%$ & $6,06 \%$ & $-11,13 \%$ & $11,64 \%$ \\
\hline Fondo B & $14,89 \%$ & $-3,70 \%$ & $11,79 \%$ & $1,07 \%$ & $2,49 \%$ & $8,27 \%$ & $4,33 \%$ & $4,88 \%$ & $-7,52 \%$ & $11,38 \%$ \\
\hline Fondo $\mathrm{C}$ & $14,96 \%$ & $-0,89 \%$ & $7,51 \%$ & $1,74 \%$ & $2,16 \%$ & $9,00 \%$ & $4,68 \%$ & $4,61 \%$ & $-3,79 \%$ & $9,34 \%$ \\
\hline Fondo D & $13,15 \%$ & $1,21 \%$ & $3,09 \%$ & $2,60 \%$ & $2,02 \%$ & $7,68 \%$ & $5,42 \%$ & $3,81 \%$ & $0,06 \%$ & $7,08 \%$ \\
\hline Fondo $\mathrm{E}$ & $9,03 \%$ & $3,07 \%$ & $1,01 \%$ & $3,89 \%$ & $0,71 \%$ & $6,78 \%$ & $5,09 \%$ & $3,15 \%$ & $4,31 \%$ & $6,71 \%$ \\
\hline
\end{tabular}

Fuente: Elaboración propia con datos de la Superintendencia de Pensiones de Chile. 
Tabla 2: tasa de rentabilidad real promedio de los fondos (2010-2019)

\begin{tabular}{|c|c|}
\hline Tipo de Fondo & Promedio \\
\hline Fondo A & $4,87 \%$ \\
\hline Fondo B & $4,57 \%$ \\
\hline Fondo C & $4,80 \%$ \\
\hline Fondo D & $4,55 \%$ \\
\hline Fondo E & $4,35 \%$ \\
\hline
\end{tabular}

Fuente: Elaboración propia con datos de la

proporción de los portfolios invertidos en instrumentos de renta variable. Lo cual, genera diversas alternativas de riesgo-rentabilidad, debido a que el riesgo de cada tipo de fondo responde al porcentaje de renta variable que posee. La Tabla 4 presenta la cota superior e inferior de la inversión en renta variable.

Dada la situación de virtual estancamiento que muchas empresas están enfrentando, es vital para las empresas poder contar con acceso al crédito que ayude a cumplir con los compromisos de corto plazo y entregue recursos para solventarlas por el período de tiempo que dure la crisis Superintendencia de Pensiones de Chile.

\section{¿DE QUE MODO PODRIÁAN LAS AFPS CONTRIBUIRA PALIAR LA CRISIS ECONOMICA QUE ESTA GENERANDO EL COVID-19?}

sanitaria, que podría ser de uno o dos años.

A principios de abril, la Asociación de AFPs dio a conocer una propuesta de formar un Fondo de US\$1.000 millones para apoyar a las Pymes, que debería contar con una garantía estatal para reducir el riesgo de no pago o default, y así proteger los ahorros de los chilenos. Temas a resolver sobre la propuesta de la Asociación de AFPs es sobre cómo se organizaría dicho Fondo, es decir cómo podría operar y llegar directamente a las empresas necesitadas.

Diversos economistas y dirigentes gremiales han apoyado la idea, ya que va en la línea de mejorar el canal de crédito en el país. Los detractores, por otro lado, argumentan sobre el potencial riesgo que enfrentarían los ahorros previsionales.

Es así como que dicha propuesta sigue siendo analizada y no se ven señales de avance, ya que hay diversos aspectos a considerar, tales como las regulaciones, y los múltiples organismos supervisores involucrados. Adicionalmente, un alto ejecutivo de AFP Cuprum comenta que se está diseñando un segundo fondo por un monto equivalente a US\$1.000 millones, pero esta vez con la colaboración de CORFO, con garantías por hasta el $80 \%$. La desventaja de este segundo fondo sería que utilizaría intermediarios no bancarios, lo que podría aumentar el costo para las empresas.

Tabla 3: cartera de inversión de los fondos de pensiones a marzo de $\mathbf{2 0 2 0}$

\begin{tabular}{|l|l|}
\hline \multicolumn{2}{|c|}{ Inversión nacional } \\
\hline Renta fija & Renta variable \\
\hline Instrumentos Banco Central & Acciones \\
\hline Instrumentos Tesorería & Activos Alternativos \\
\hline Bonos de Reconocimiento y MINVU & Fondos de Inversión/FondosMutuos \\
\hline Bonos de Empresas y Efectos de Comercio & \\
\hline Bonos emitidos por Fondos de Inversión & \\
\hline Bonos Bancarios & \\
\hline Letras Hipotecarias & \\
\hline Depósitos a Plazo & \\
\hline Fondos Mutuos y de Inversión & \\
\hline Activos Alternativos & \\
\hline Disponible & \\
\hline Derivados & \\
\hline Otros Nacionales & Alternativos Otros \\
\hline & Fenta variable \\
\hline Renta fija & Fondos Mutuos \\
\hline Derivados & \\
\hline Otros Extranjeros & \\
\hline & inversión extranjera \\
\hline
\end{tabular}

Fuente: Elaboración propia con datos de la Superintendencia de Pensiones de Chile.

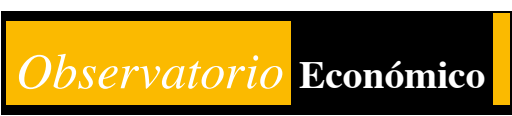

Decano: Eduardo Abarzúa Fono Facultad: 28897366 fen.uahurtado.cl

Tabla 4: limites de inversiones en renta variable

\begin{tabular}{|l|c|c|}
\cline { 2 - 3 } \multicolumn{1}{c|}{} & $\begin{array}{c}\text { Límite } \\
\text { Máximo } \\
\text { Permitido }\end{array}$ & $\begin{array}{c}\text { Límite } \\
\text { Mínimo } \\
\text { Permitido }\end{array}$ \\
\hline Fondo A & $80 \%$ & $40 \%$ \\
\hline Fondo B & $60 \%$ & $25 \%$ \\
\hline Fondo C & $40 \%$ & $15 \%$ \\
\hline Fondo D & $20 \%$ & $5 \%$ \\
\hline Fondo E & $5 \%$ & $0 \%$ \\
\hline
\end{tabular}

Fuente: Elaboración propia con datos de la Superintendencia de Pensiones de Chile.

En paralelo, el Gobierno impulsó un proyecto de ley, ya aprobado por el Congreso, que inyecta hasta US\$3.000 millones de dólares en garantías para créditos a empresas con ventas de hasta UF $1 \mathrm{mi}$ llón, lo que cubriría cerca del $99 \%$ de las empresas del país, esto es 1,3 millones de empresas. Con este aporte a modo de garantía, se espera que los créditos asciendan a US $\$ 24.000$ millones. El éxito de este programa depende de que los bancos comerciales adheridos, que abarca a cerca del $90 \%$ de las colocaciones, otorgue la llamada "línea de crédito Covid-19" para financiar capital de trabajo, cobre como máximo una tasa de 3,5\% anual, otorgue seis meses de gracia para comenzar la devolución del préstamo y que se pague en cuotas que van desde 24 a 48 meses.

Cabe señalar que se espera que los bancos comerciales canalicen los créditos, y que las empresas que lo reciban, hagan buen uso de estos recursos, y logren retomar sus actividades comerciales, con los niveles de empleo, previos a esta crisis.

Son interesantes las propuestas de la Asociación de AFPs en conexión con los problemas actuales de la sociedad provocada por la pandemia del Covid-19. Sin embargo, la creación de un Fondo tal como está planteado requiere el aval del Estado que limite las posibles pérdidas. No obstante, debido a que el Gobierno ya lanzó un ambicioso programa por hasta US\$3.000 millones en garantías, es poco probable que éste quiera avalar nuevos programas, hasta ver los resultados de la iniciativa ya aprobada.

\section{UNA PROPUESTA}

Una alternativa disponible para las AFPs, que conlleva cambios regulatorios menores, y que podría contribuir con la cadena de financiamiento para una gran base de empresas es permitir que las AFPs puedan invertir, a través de fondos de inversión públicos, en facturas y pagarés.

El mecanismo de invertir en activos a través de un vehículo de inversión, como es un fondo de inversión púbico, se le llama inversión indirecta. Al contrario, cuando una AFP invierte en un determinado activo, sin pasar por un vehículo de inversión, se le llama inversión directa.

La principal característica de las facturas y pagarés es que son ubicuas a las actividades comerciales de empresas Pymes y grandes empresas. Estos instrumentos representan un compromiso de pago que, dado su bajo monto promedio y corta duración, no son factibles de ser sujetas a una clasificación de riesgo. Desde un punto de vista práctico, considerando el gran número de este tipo de instrumentos, su bajo monto promedio y su corta duración, no es razonable pensar que las AFPs pudieran invertir en ellas de modo directo. Ya que la AFPs tendrían que transformarse en Factoring. Desde un punto de vista regulatorio, al ser facturas y pagarés clasificables como deuda privada y al no existir una aprobación genérica en el Régimen de Inversión para deuda privada, las AFPs tendrían dificultades para invertir directamente en estos instrumentos

Por lo tanto, la alternativa es que las AFPs puedan invertir en facturas y pagarés de modo indirecto, esto es, a través de vehículos de inversión, tales como los fondos de inversión públicos regidos por la Ley 20.712 , que se especialicen en facturas y pagarés.

En el mercado local ya existen fondos de inversión que compran facturas a empresas de factoring. Con esto aportan al ciclo de liquidez de las empresas. Cada fondo de inversión define su política de inversión y el nivel de riesgo que desea tomar. Las AFPs podrán elegir dentro del abanico de posibles fondos de inversión, aquella combinación de riesgo retorno aconsejable para cada uno de sus fondos administrados.

Dado que facturas y pagarés están presentes en el quehacer diario de empresas de todo tipo, es una interesante alternativa para que las AFPs inviertan indirectamente en estos instrumentos, lo que podría lograr profundizar este mercado y facilitar el financiamiento de las empresas, en particular ante la crisis económica causada por Covid-19. $\mathbf{E}$ 